\title{
Introduction
}

\author{
In the Direction of Kedar
}

When one had almost reached the Hindu shrine of Kedarnath, there used to be a point along the footpath following the Mandakini River where, in good weather, the top of the temple came into view against the backdrop of a bright, wide Himalayan panorama. In the related languages of Hindi and Garhwali, such vantage points bear the title of "Sight-of-God" (Hindi: devdarshini, deodekhni). Devdarshini is the point from which you are first able to glimpse the deity of a particular place, in this case Shiva in his Kedarnath form. Before June of 2013, devdarshini was located above the western bank of the Mandakini River, about two kilometers from the temple and twelve kilometers from the beginning of the footpath in the village of Gaurikund. The temple of Kedarnath lies on the valley floor at almost 3,600 meters above sea level, enfolded on three sides by mountains. Almost all travelers to Kedarnath, from perennial residents to first-time visitors to non-Indian regular visitors such as myself, used to stop at devdarshini to catch their breath, encounter the view, and take stock of the place where they were about to arrive.

Devdarshini often evokes a strong response. I once spoke with a woman from the Indian state of Maharashtra who had come to Kedarnath seven times. ${ }^{1}$ She said that when she arrived at devdarshini she experienced what in Hindi is called sakshat darshan-a visual encounter with (or more technically a visual knowing of) the divine in its most true form. For her, sakshat darshan meant that from this point she saw the entire Himalayan panorama as the face of Shiva. On her pilgrimage to the region in the 1920 S Sister Nivedita $(1928,39-40)$, a famous AngloScot-Irish disciple of Swami Vivekananda, described the moment of devdarshini in this way: "At last comes the moment when the temple is visible for the first time. A shout goes up from our carriers and many prostrate themselves. We press forward, 


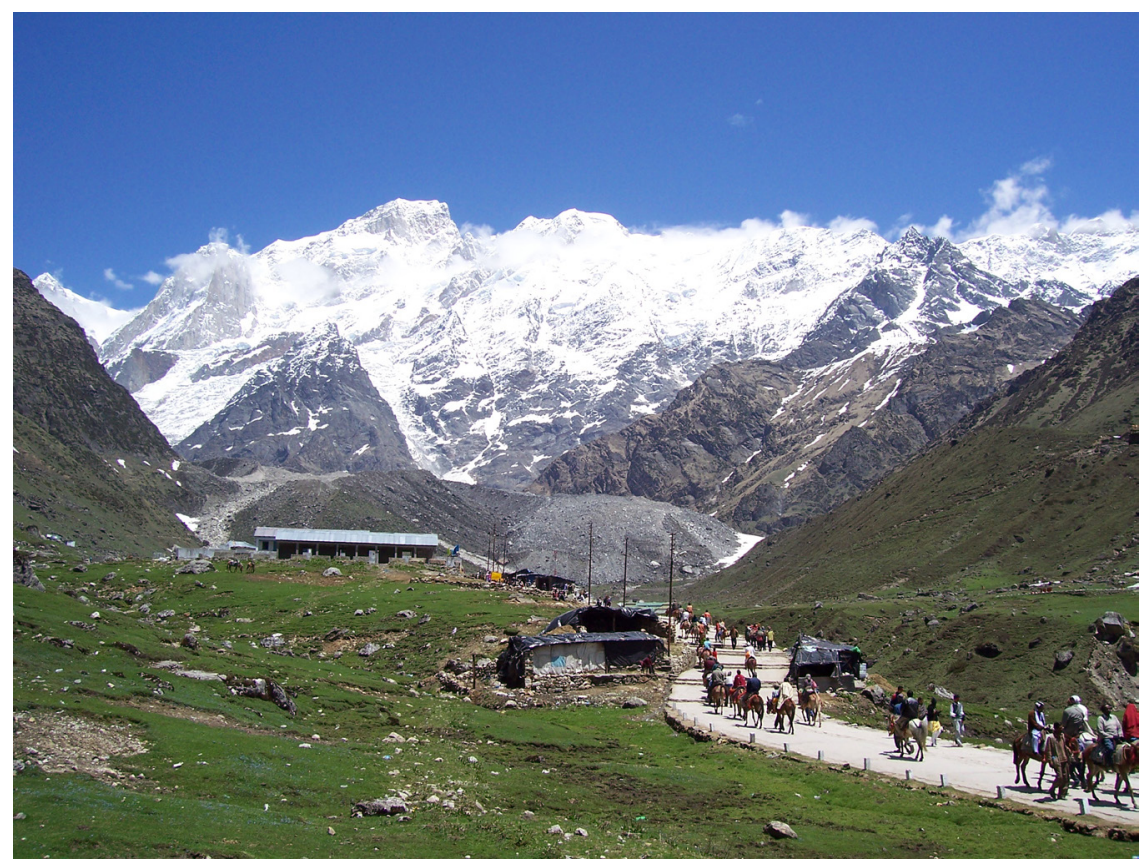

FIGURE 1. Approaching Kedarnath.

more rapidly than before." The sight of devdarshini functions as a moment of relief and inspiration for visitors to Kedarnath, many of whom are finding themselves in the Himalaya and at high altitude for the first time in their lives as part of their performance of what is known as the Uttarakhand Char Dham Yatra (Hindi: Uttarakhand Four Abode Pilgrimage). Yatra is originally a Sanskrit word that could be reasonably translated as "pilgrimage." Today in many South Asian languages the term yatra possesses a semantic range that includes everything from "pilgrimage" to "vacation" to "tour." The Uttarakhand Char Dham Yatra is a journey to the abodes of four deities: Yamunotri (of the goddess/river Yamuna), Gangotri (of the goddess/river Ganga), Kedarnath (of the god Shiva), and Badrinath (of the god Vishnu). This journey involves travel by bus, car, foot, and pony over hundreds of kilometers of Himalayan terrain and is typically carried out in the short period of approximately twelve overwhelming, draining, transformative days. In recent decades performance of the yatra by helicopter has also been increasing in popularity - that is, in good weather. The Uttarakhand Char Dham Yatra is one of the most popular yatra journeys in North India today.

The sight at devdarshini of the white glaciers flowing down into the darkness of the lower mountains, divided by waters of the Mandakini River, which is one of the Himalayan tributaries of the Ganges, localizes the famous story of the descent 


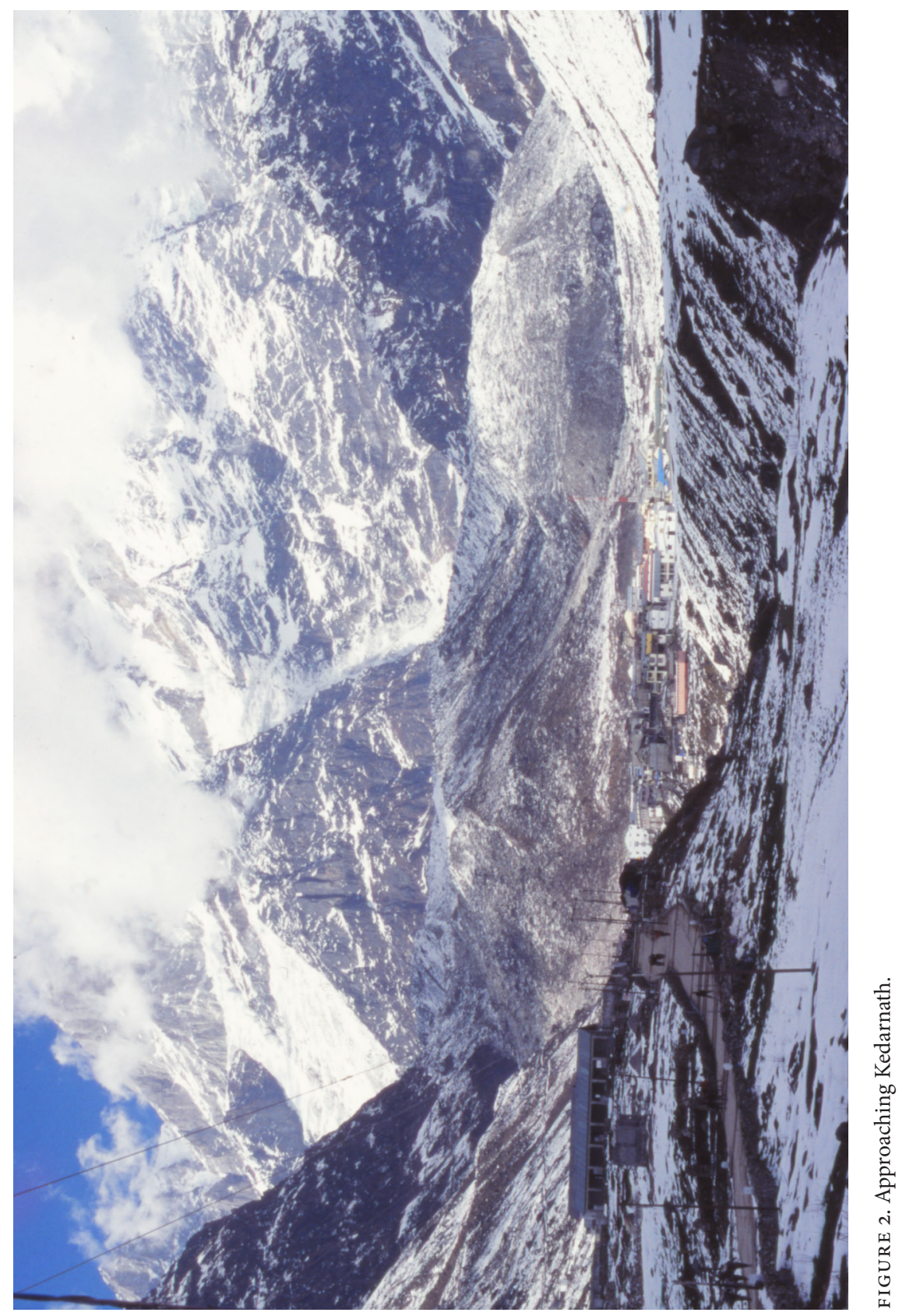


of the goddess Ganga in her river form into the world and underscores Shiva's relationship to the Goddess in her aquatic manifestations. Ganga descends at the request of King Bhagiratha, who has performed thousands of years of ascetic practice so that the souls of his ancestors may be purified through the presence of Ganga on earth. Ganga finally assents but says that her unfiltered power would be too much for the earth to bear. Thus a mere trickle of the full power of the Ganga exits the protective filter of Shiva's matted hair and enters our world. This panorama also evokes perhaps the most common act of ritual devotion to Shiva, the pouring of water over a linga. Linga is a difficult word to translate. Diana Eck $(1999,4)$ expresses it in this way: "the simple stone shaft that is the symbol of Shiva." ${ }^{2}$ It is the complicated, fluid, indexical sign of Shiva's presence in and relationship to the world. ${ }^{3}$ Shiva's presence in Kedarnath specifically is "selfmanifest" (Sanskrit: svayambhu). He dwells, not in a form created by human hands, but rather in a form that was always already there. Further, his relationship to the devotee is not stable. In many ways, serious devotion to and worship of Shiva place the practitioner on the path to becoming a Shiva, a multiform of God. As Richard Davis $(1991,52)$ translates an important phrase of Shaiva (Shiva-oriented) ritual: "Only a Śiva can worship Śiva." The panoramic view, then, indexes not only the nature of the cosmos and the self-manifest nature of the god but also the personhood of the visitor who is taking in the view. It registers, both inwardly and outwardly, the fluid "oscillation" or "pulsation" that is the "ubiquitous principle of a dynamic universe, governing all creation" (42). The panorama of Kedarnath on a clear day fuses iconic, aniconic, and natural modalities for experiencing, worshipping, and becoming the conjoined presence of Shiva and Ganga in this world. Kedarnath is an especially storied place in the already legendary Himalayan region of Garhwal, famously known and marketed today as the Land of the Gods (Hindi: Dev Bhumi). Let us proceed to Kedarnath itself, the next step in exploring what the recent history of this complex, powerful place has to teach us about how religious worldviews frame human-nature relationships in the twenty-first century.

\section{MEETING KEDARNATH}

The village of Kedarnath, whose defining feature is the temple, lies on the valley floor at the upper edge of the Lesser Himalayan mountain range, quite a bit higher than the altitudes at which most Garhwalis live. Kedarnath occupies a distinctive place in the networks of modern Hindu pilgrimage destinations. It is difficult to reach. In recent decades the road ended in Gaurikund, about 1,800 meters in altitude and fourteen kilometers in distance short of the temple. Yet at the same time Kedarnath had become a major destination. Approximately half a million people visited Kedarnath in 2007. It is not in the same category of inaccessibility as 


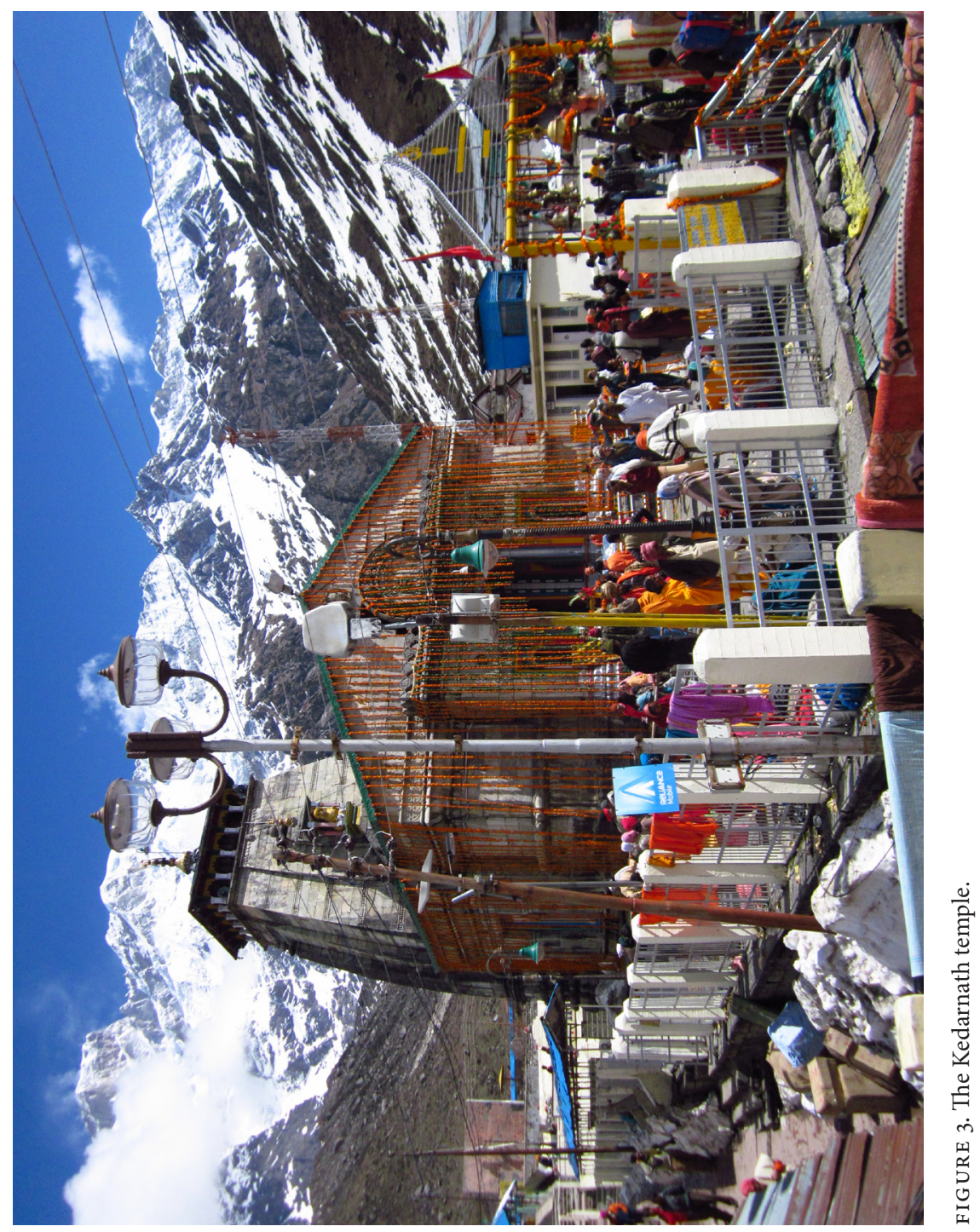




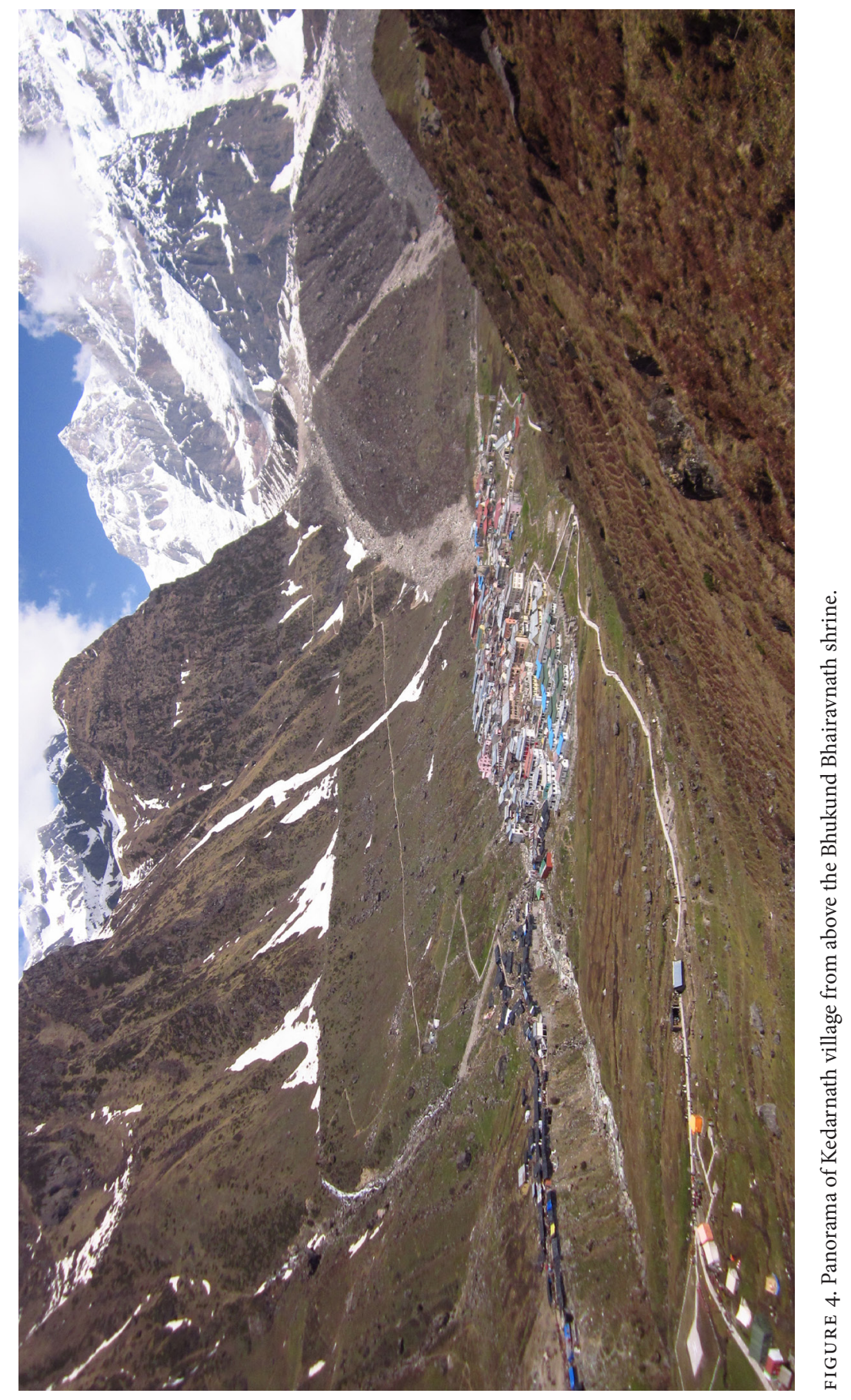


a journey to the famous Mount Kailasa, or even the arduous journey to Amarnath, where Shiva dwells in the form of an ice linga. But it has remained a Himalayan pilgrimage destination evocative of the difficulty of premodern yatra to the Himalaya even as the number of its visitors has risen.

Kedarnath is a "crossing-over place" (Sanskrit: tirtha) - a place that offers the possibility that one can "cross over" or "ford" the ocean of rebirth. It is a place that provides special access to that which is underneath and over and within and beyond. It is a place that grants wishes, heals, and purifies karma. It is a dham, an abode or dwelling place of a deity. Kedarnath is best viewed primarily as a dham, an especially powerful abode of Shiva. More specifically, along with Manimahesh in modern-day Himachal Pradesh, Amarnath in Jammu and Kashmir, Kailash Mansarovar in Tibet, and Pashupatinath in Nepal, Kedarnath is one of the most famous places where Shiva is understood and experienced to dwell in the Himalaya, the mountain range that is famously both his father-in-law and his preferred residence, the place where he can pursue his yogic practices in natural solitude. It is one of twelve jyotirlingas, twelve locations spread throughout India where Shiva's universal form of a vibrating column of light embeds itself in the ground. ${ }^{4}$ The linga contained in the temple is the focal point of Shiva's presence in Kedarnath. It is svayambhu - an a priori presence in the form of a roughly triangular piece of mountain rock that emerges from the ground and that muddies the relationships among god, place, and cosmos. This dwelling happens inside and outside the temple.

Kedara is a Sanskrit word that means marshy ground, soil mingled with water. It is usually glossed in Hindi with the term daldali bhumi, or swampy land. It occurs when and where snowmelt, rain, and river water turn the ground into a marshy ooze of varying consistency. Thus the name Kedarnath (Kedaranatha or Kedareshvara in Sanskrit) literally means "Lord of the Marshy Ground." It is both a place-name and a name for Shiva. The entire Kedarnath end-valley, starting from near devdarshini, lies buried in snow for approximately half the year. The snow melts and the end-valley is snow-free for most of the summer pilgrimage season, with the exception of the occasional snowstorm. For travelers on the path the most common greeting is "Jai Kedar" or "Jai Shri Kedar," a greeting and naming that addresses both the place and the god. It is one of many signals that Shiva is felt both inside and outside the temple-a theme that runs through most if not all aspects of the place of Kedarnath.

Old stories about Kedarnath enshrine this location as a point of transition and exit out of the human world. It is one of the places associated with the Climb to Heaven (Hindi: swargarohan) of the five Pandava princes and their joint wife Draupadi. Desperate to cleanse themselves of the karma generated during the massive civil war narrated in the Mahabaharata epic, the Pandavas head to the Himalaya as renunciants, leaving the political world behind. They walk up into 
the Himalaya and thence to heaven on what is known as the Mahapath/Mahapanth, the Great Path. The oldest brother, Yudhishthira, does so without leaving behind his physical body. This feat aligns itself with one of the central themes of tantric practice-liberation through the body as opposed to liberation as exit from the material world. The Kedarakalpa (Sanskrit: literally "account of Kedara"), a late tantric text of uncertain date, tells the story of five spiritual adepts who walk a version of the Great Path into the mountains that passes through the Kedarnath locale and beyond into the abode of Shiva (Goswamy 2013; Viśâlmani Śarmā Upādhyāy 1952; Padumā and Hajārībāg 1907). In the narrative worlds that touch on Kedarnath one finds a sense of the place as a limit point, a door to zones beyond.

\section{THE FLOODS OF 2013}

Recently Ganga gave the world a small taste of her fuller power that is normally held in check by Shiva as she descends into our world. The circumstances underscored the idea so clearly attested in the story of the Pandavas that Kedarnath functions as a place of crossing between life and death. In 2013, the monsoon came to Uttarakhand early and with special force. Intense rains resulted in widespread floods and landslides. Because it was the height of the summer pilgrimage season, over seventy thousand yatris were stranded, and by extremely conservative estimates hundreds of locals and yatris perished (Tripathi 2013; BBC News India Staff 2013a; Zee Media Bureau and Press Trust of India 2013). The floods and landslides prompted massive rescue and relief operations, a drama whose plot occupied (and continues to sporadically receive) national attention. Kedarnath was hit with two flood events, the second a truly dreadful wave of water and debris that resulted from the bursting of a natural debris dam on a snowmelt-fed lake located just above the village of Kedarnath to the northwest. By even the most conservative of estimates, hundreds of people in and around Kedarnath did not survive (table 1).

One early assessment of the impact of these flood and landslide events was carried out by Ravi Chopra (2014), director of the People's Science Institute in Dehra Dun. As this preliminary assessment makes clear, the events traumatized the region. Yet much of the trauma could have been avoided, for the impact of the flooding was multiplied by the lack of a well-developed disaster relief plan; insufficient sensitivity to meteorological warnings; insufficient acknowledgment of and planning for the clear, obvious likelihood of this kind of flood event; insufficient government regulation of the number of visitors; lack of alternate escape routes; unregulated construction of private and commercial building in floodplains and near riverbanks; lack of sufficient understanding about how human-built dams affect what happens to a river during floods that bring increased water volume and, more significantly, debris flow and muck; and the short-sighted widening of roads built in landslide-prone areas. 
TABLE 1. Preliminary Statistics on the Uttarakhand Floods of 2013

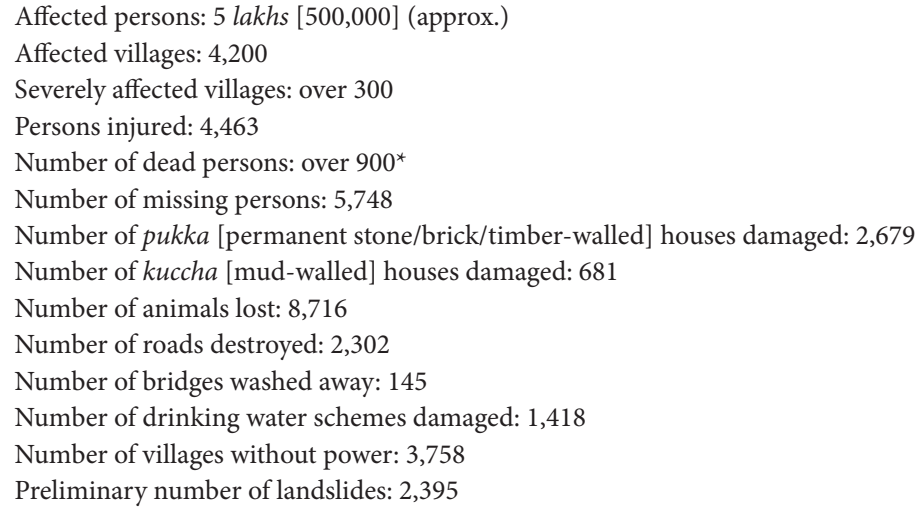

In short, much of the impact of the floods and landslides would have been vastly mitigated by better planning, road and building construction, and regulation. Fewer would have died and been injured. The water and debris would have destroyed fewer buildings and roads. Travel to the region in immediately subsequent years would not have declined as far as it did, and locals would probably have invested more soberly and sustainably in commercial infrastructure before the floods and would have experienced less severe financial loss afterwards. As journalist Jay Mazoomdaar (2013) put it in his article "How Uttarakhand Dug Its Grave," "A state created to safeguard the hill people, has become a graveyard of pilgrims and local aspirations in just over a decade."

After June of 2013 Uttarakhand entered a highly public recovery mode, and Kedarnath has been one of the visible, important, and contested symbols of how Uttarakhand should move forward during this process. For visitors, the vast majority of whom were Indian, the scope of the disaster was a betrayal of expectations-the modern twenty-first-century nation-state should be able to give advance warning of events like this and be prepared to hit the ground running in the aftermath, particularly after the Indian Ocean Tsunami of 2004. Yatra in the Himalaya was supposed to have become a journey for the whole family. For Uttarakhandis the sense of betrayal and anger went deeper. The region that in 2000 became the separate state of Uttaranchal (and was later renamed Uttarakhand) has been marked since the late 1800 s by contestation between local mountain residents and outside forces (the British colonial government, British timber companies, the Indian Forestry Department, the Uttar Pradesh state government 
from which Uttarakhand broke away in 2000) over the control of natural resources such as forests and rivers. It is the region that in the 1970s popularized the tree-hugging movement (known in Garhwal as Chipko) and saw the construction (also begun in the late 1970s) of what would be one of Asia's largest civil engineering projects, the Tehri Dam. Traditions of protest and resentment surrounding the exploitative extraction and control of natural resources during the colonial and postcolonial period ultimately created the conditions for the creation of a separate state that, according to Pampa Mukherjee (2012, 201), was founded on a "strong alternative vision of development" attuned to the human and ecological needs of the region.

This did not happen. Instead, much of the state, both inside and outside the state government, ignored what tourism studies would call the "carrying capacity" (Coccossis and Mexa 2004) of the region so that it could service the growing number of visitors to the region and the growing demand for electricity. For some, this disaster registered at least partially as the anger of Shiva at the de-sacralization of the region as it embraced ever-growing levels of pilgrimage tourism. For others, the tragedy was largely a human tragedy of poor planning, greed, and systemic miscalculation. For many, it was both. The devdarshini I knew has been washed away and a new path has been built on the eastern bank of the Mandakini. The village is now partially enclosed to the north by a massive set of protective walls. The temple courtyard now includes a massive boulder whose bulk protected the temple during the floods.

This is the reason that much of what I have written, so far, has been in the past tense. Much is different today, and everything that I saw before 2013 now, in hindsight, feels like foreshadowing. Even in good weather in Kedarnath there was always a sense of unpredictability, of an uncertainty built into the ground. Journey to this place of divine hyperpresence has never been without risk. The precarity of human presence in the challenging environment of the Himalaya, where earthquakes and landslides go with the territory, is something that has been fundamental for humans living in and visiting the Himalaya for millennia. ${ }^{5}$ This reality reasserted itself with new force in the twenty-first century. Both locals and yatris often reminded me how difficult it was for anyone to reach Kedarnath. Finding oneself in Kedarnath for any reason was at some level a karmic triumph. During even a normal pilgrimage season the monsoon rains cause landslides that block the road, and visitors may find themselves stranded in a mountain valley whose modern infrastructure is suddenly revealed to be skin-deep, a tracery on the surface of the land. On June 21, 2013, as reports continued to come in about the number of dead in and around Kedarnath, I remembered a conversation I had once had with a Kedarnath pilgrimage priest (Hindi: tirth purohit) in which he remarked (my paraphrase) that Kedarnath was not a place where humans were meant to live. ${ }^{6}$ 
We can best understand the floods of 2013, particularly in the Kedarnath valley, by situating these terrible events within their broader ecological and religious contexts. The power and importance of Kedarnath are a tapestry woven out of many threads: place-based concerns about life in the Himalaya, transregional devotion to a famous god, tourism from across India and around the world, and the particular environmental history of the central Indian Himalaya. This environmental history includes two issues critical for life in the twenty-first century: deforestation and the control of water. The floods of 2013 and their aftermath rendered the interdependence of these threads terribly, publicly clear. We must try and learn what we can from this moment of awful transparency. The case of Kedarnath offers an opportunity for thinking through not only the nature of these interdependencies (which for many is already not surprising) but also the longer stories of how foundational factors structure this overall web of connection. And here we arrive at the central argument of the book-an argument for a way to image this interdependence and its implications. For centuries, the enmeshing of Shiva with the Himalayan environment has animated how Hindus conceptualize and experience Kedarnath. Shiva is both inside the temple and part of the Himalayan place itself. The fluid overlap of place and god frames, in important ways, the place as a whole. Over time this long-term pattern of the place combined with region-specific changes in land use, a postcolonial pattern of regulatory myopia about Himalayan environmental realities, and in recent decades a massive, rapid rise in the number of visitors to the region. It was at this point that the situation became a ticking bomb that encouraged short-term, selfish and self-motivated action by those with livelihoods connected to pilgrimage tourism in Uttarakhand. In important ways the terrible power rampant during the floods was not a departure from noncatastrophic times. Landslides, floods, and earthquakes are to be expected in the Himalaya-such power is always latent in the mountain landscape. What the aftermath of the floods laid bare was that in recent decades the situation in Uttarakhand made this well-known fact easy to forget.

It will be impossible for many years to visit or even discuss Kedarnath without beginning from the time of the disaster. However, what happened in 2013 is best understood in the broader context of how people have understood and experienced Kedarnath both in the recent past and in earlier times. In writing about the conditions leading up to and the reactions after a disaster in a place of religious significance, a balance must be struck between a commitment to an urgent critique that is rooted in the recent past and the necessity for placing that recent past in broader context. To address this analytic challenge I work with the idea of a place's "persistent patterns"-persistent not because the place has been frozen in time but rather because the pattern is the continually emergent result of particular 
and changing constellations of culture, environment, and political economy (F. Cho and Squier 2013, 360). This feature of the place, its "persistent patterns," functions as a point of commonality among people who find themselves there for a variety of different reasons: as tourists, as pilgrims, as laborers, as service providers, as guides, as shopkeepers, as priests, and as employees of the government. I argue for the importance of noticing a particular persistent pattern: a longstanding ambiguity about the specifics of how Shiva inhabits Kedarnath that has demonstrably informed experiences, conceptualizations, and representations at many different moments in the recorded history of this place. The terrible events of 2013 are part of the broader persistent pattern of Kedarnath and, when viewed in a certain way, help us see things about this broader pattern that might not otherwise be easily visible.

The disaster in 2013 publicly affirmed the ambiguous, fundamentally Himalayan and Shiva-oriented character of Kedarnath. At the same time, the floods made it clear that the patterns of commercialization, development, and regulation of recent decades in Uttarakhand, patterns that both had arisen in response to new statehood and an influx of middle-class pilgrims and tourists and were the continuations of policies first employed by the British in the nineteenth and early twentieth centuries, were starkly out of place. The floods underscored a persistent geological fact about life in the Himalaya that had been underemphasized in recent decades of road and hotel construction: floods, landslides, and earthquakes are an inescapable part of this mountainous, seismically active terrain. The sense of both consonance and dissonance with the Kedarnath (and more broadly the Garhwal Himalaya) of earlier decades and centuries is at once religious, economic, political, and ecological. People connected to Kedarnath today therefore understand both the disaster and the recent short-sighted development that multiplied the impact of the disaster both as the consequence of human disregard and as an indication of a growing disconnect with the Himalayan environment and its resident divine powers. As local and regional stakeholders took charge of the reconstruction of Kedarnath with a national audience in mind, religious understandings about Shiva, the Himalaya, nature, and the power of river goddesses infused the push for a more ecologically sound and economically viable brand of pilgrimage tourism and regional development. Uttarakhandis and visitors to the region for years to come will grapple with the short-term and long-term economic, cultural, and moral costs, both to themselves and to others, of the practice of pilgrimage tourism in the central Indian Himalaya. The floods of 2013 provoked a largescale referendum on questions of appropriate development in the central Indian Himalaya. It is the task of this book to contextualize, in a Kedarnath-centric way, the beginnings of a new post-2013 chapter in the ongoing story of this region. Doing so will offer a portable, holistic model for thinking about how religious worldviews inform conceptions, experiences, and practices connecting to the 
natural world that can be deployed across multiple scales. Below I suggest that the idea of "the experience of place as an eco-social system characterized by complexity" is a useful way to conceptualize this situation as a whole. But this way of thinking about the Kedarnath situation does not fully describe or understand who and what is present in and around this place. What analytic framework could?

\section{THE PURPOSES OF THIS BOOK}

In 2010, when I had left Kedarnath and passed devdarshini going back down to Gaurikund, a commercial helicopter carrying yatris flew overhead. I was taking a picture of a yatri who had chosen to ride a pony up to Kedarnath rather than walk. The choice to ride a pony had in recent years become increasingly popular (Whitmore 2016). At that time, I had seen the presence of a helicopter overhead as the most visible evidence of how Kedarnath was becoming more and more of a destination for middle-class and upper-middle-class Indian yatris. Today, the sight of helicopters in the Kedarnath valley carries an additional association. Helicopters in 2013 were almost the only way that the government could reach those stranded by floodwaters and washed-out roads. For much of 2013 they were the only way to deliver supplies to the area, but often the weather conditions in the Kedarnath valley prevented even helicopters from making the journey. One of the most urgent priorities in the early reconstruction of postflood Kedarnath was the construction of landing pads capable of supporting the weight of heavy cargo helicopters.

As this place has changed, so too have my responsibilities as a scholar. This is intended to be a book about a place that shows how attending to the emplacement of religion helps us understand the relationships of ecology, disaster, and development. In many important ways, Kedarnath-as-place is the central character in this story. This approach emerges from numerous ethnographic encounters and my responsibilities to those about whom I write. During an eighteen-month fieldwork period in 2006-8 I spent as much time as I could in Kedarnath. This meant approximately six months during 2007 and three weeks of 2008. I have since visited Kedarnath briefly in 2011 and 2014 and the Kedarnath valley (but not Kedarnath) in 2017. The longest I spent in Kedarnath itself without respite, for reasons of health, logistics, and research, was about two months. During these periods of time I attempted to learn from and about as many different kinds of people as possible. I spoke with yatris from all over India and the world. I made sure to spend time with tirth purohits (Hindi: pilgrimage priests), employees of the Badrinath-Kedarnath Temples Committee, police, shopkeepers, and pilgrim rest house and lodge managers from different parts of the Kedarnath valley, contractors and cleaners from the plains, Nepali laborers, renunciants, and Western visitors. I spent most of the 
remaining months of that fieldwork period further south in the Kedarnath valley in Ukhimath, the administrative center for the division of the Rudraprayag district in which Kedarnath is located. This time was itself punctuated by trips to the British Library in London for information about Kedarnath in the India Office Library and to the Scriptorium of the Sanskrit Dictionary Project in Pune for references to Kedarnath in Sanskrit literature. While based in Ukhimath, I spent most of my time introducing myself to the three valleys of the Kedarnath valley system. I visited dozens of villages and important shrines in these three valleys so that I would understand how Kedarnath fit into its local contexts and so that I would have a connection to persons working in Kedarnath who came from all these places. I was able to carry out and record structured and semistructured interviews with Kedarnath and Kedarnath valley residents and several renunciants.

My overriding goals, formed by this time in Garhwal, have been to shape the book in a way that would allow a serious reader to imagine something of what it feels like to stand in Kedarnath at the beginning of the twenty-first century and at the same time see the broader and longer contexts that surround these recent decades. This has meant marshaling a number of approaches from across the humanities and social sciences in service of a very specific kind of descriptive holism. The goal of this description is to bring the reader partially into the community of those who have been to Kedarnath in a way that inspires long-term concern for the place and the region and the broader social, cultural, economic, political, environmental, religious, and ecological processes that flow through and center on Kedarnath. There is much to learn from the case of Kedarnath as we continue to orient ourselves to life in the twenty-first century, framed as it is by the increased flow of people and capital, shifting environmental realities, the persistent embedding of what some would call "religion" in how people understand themselves and others to be in the world, and the recognition that we are more a part of our world than many of us have realized.

This approach to writing about Kedarnath has been my response to the idea that, as Laurie Zoloth $(2015,374)$ puts it in her contribution to a special issue of the Journal of the American Academy of Religion on climate destabilization, "scholars in the humanities have duties to the world." Todd LeVasseur $(2015,297)$, in his introduction to the same special issue, poses this question: "What does it mean to be a religious studies and/or a biblical scholar professional, working as an employee at an institution of learning on a biophysical campus, on a planet undergoing rapid anthropogenic climate destabilization?" While the exact causal relationships between the floods of 2013 in Uttarakhand and the global phenomenon of anthropogenic climate change are not yet wholly clear (I discuss this more in the body of the work), it is very clear that much of the impact of the disastrous flooding was human caused, making Kedarnath a natural disaster with 
an "unnatural history" (Steinberg 200o), or, more bluntly, an unnatural disaster. But whatever the exact causal, scientific explanation may be for why the floods of 2013 happened in Kedarnath and across Uttarakhand in the way that they did, these events should be understood as exactly the kind of unnatural disasters that have already increasingly begun to mark the twenty-first century and that will inevitably disproportionately affect residents in the Global South. This is something that I have come to understand as part of my own journey in writing this book. I did not begin my career as a scholar of human ecology or even of what can now be called the subfield of ecology and religion. In recent years of thinking about this project I have followed my concern for what happened to people I know who live in the Kedarnath valley into these fields of study. I have arrived at the rather unsurprising conviction that the better we are able to understand the relationship between religious worldviews and the ecosystems of which humans are but a part, the more likely it is that particular forms of human action and environmentrelated policies of land use, consumption, investment, regulatory oversight, and more broadly "development" will be genuinely sustainable in longer-term and relatively less harmful ways. Therefore, my goal in this work is to describe this situation in a way that will be useful for those far better placed than I to act in ways that will have material benefit.

I therefore assemble Kedarnath-related data into a general picture in order to give a particular sense of the whole place that I hope will serve these goals. The design of the book aims to allow the reader to feel the argument and acquire a sense of the place and its longer story in a way that showcases the utility of an approach grounded in religious studies for understanding lived, emplaced human situations, particularly in the Himalaya (on this point, see Drew and Gurung 2014). I hope this book will also serve as an aid to people who work with questions of ecology, climate change, development, and tourism and who require a nuanced understanding of how cultural and religious contexts bear on such matters.

\section{BHUPENDRA}

It is, however, impossible to proceed further without introducing Bhupendra Singh Pushpwan, my friend and research associate. His notes, thoughts, questions, and insights infuse this book. He was in Kedarnath when the floods came and did not survive. I knew Bhupendra first as a friendly local, then as a schoolteacher, then as a research assistant and guide, and most importantly as a friend. Somewhere along the way I realized that he made a practice of befriending foreign tourists and becoming their guide, one of several Ukhimath men who do so, a logical and inescapable framework of relationship that would inevitably structure much of our encounter. 
Bhupendra often had to patiently explain to me basic things about Garhwali culture and the Kedarnath valley and to tolerate my numerous idiosyncrasies and physical infirmities. I remember once, above Kedarnath when we went to gather Brahma lotuses to offer in the Kedarnath temple and were therefore required to walk barefoot, I walked so slowly that he took naps while waiting for me to catch up. I often had to reiterate my research aims because they were different from what he initially understood the object of my research to be. In one of our first official research meetings together, he offered me a series of quotations from the Bhagavad Gita that he had personally selected and that he thought was what I was looking for; I wanted to talk to him about how to start meeting and interviewing Kedarnath pilgrimage priests. My research allowance for a month was more money than he would make in a year. I was a white American working on a doctoral degree; he was an Indian pahari with what was called, in Ukhimath, ten plus two, two years of study in intercollege after ten years in primary and secondary school. And yet at the same time we found that we had much in common. We both thought of ourselves as late bloomers in life.

After my first several months in Ukhimath, I spent most of a year working closely with Bhupendra. We lived, cooked, and ate in the same room in Kedarnath during the 2007 season. He taught me how to cook dal, vegetables, and roti. $\mathrm{He}$ took me, reprising his sometime role as mountain guide, to the many villages and shrines of the Kedarnath valley that we agreed were important for my work. We once climbed up behind Kedarnath to see Chorabari Tal (also known as Gandhi Sarovar), the snowmelt-fed lake that would fall on Kedarnath in 2013. We carved "Luke and Bhupi" into a rock that probably later fell on Kedarnath. I went over with him, more than anyone else, how to phrase my questions, and often he would add his own. He advised me on when to participate, when to lie low, when to push. He had a gift for intercultural communication and clarity of expression; his background as a teacher served him well in his work with me. I think that working with me gave him the chance to exercise his considerable intellectual gifts much more than in any other job he had found so far in his life. I have belatedly realized that the clearest formulation of what I have come to understand as the eco-social complex power of Kedarnath came from Bhupendra when, during a walk, he turned to me and said, "Nature is the face of God." Many of my relationships with residents of the Kedarnath valley began through Bhupendra rather than through my own efforts or merits. His willingness to vouch for my worth paved the way for much of my work. After working with me, he went on to secure a job with an international nongovernmental organization and then later found his way back to Kedarnath working for a helicopter company, which is why he was in Kedarnath when the floods came. He leaves behind his parents, a younger brother, a wife, two children, and a village full of friends and family who miss him deeply. I hope that in some way this book will publicly illustrate what those close to Bhupendra 
already knew but perhaps he never fully managed to show the world: that he was an extraordinarily wise, kind, perceptive, and honorable person.

\section{THE POWER OF KEDARNATH}

Kedarnath is a place full of power. I use the term power primarily as a rough translation of the term shakti. Shakti, in both Hindi and Sanskrit, means "force," "power," "energy," and "authority." Shakti can also refer to one form of Mahadevi, whom some scholars term the "Great Goddess" of Hindu traditions. It is also a term that can be used to describe physical and social power and authority. Kathleen Erndl $(1993,32)$ has translated the shakti of Mahadevi as the "dynamic force inherent in matter." I trace the beginnings of my understandings of the shakti of Kedarnath to a rough memory of a conversation at the top end of the Kedarnath bazaar with a Kedarnath pilgrimage priest whom I will call Bagwadi-Ji, sitting against the wall of a lodge fronted by shops selling materials for ritual worship (Hindi: puja) along with pictures and books about the Uttarakhand Char Dham Yatra. ${ }^{7}$ We were looking at the ebb and flow of people in the bazaar and in the temple courtyard just up the steps. Some were making reverences when they approached the temple. Some were snapping photographs and looking at the mountains. Some were tired and determined sedan-chair bearers who were carrying their charges all the way to the door of the agreed-upon destination. Some were seated ascetics (Hindi: sadhu) offering blessings and asking for donations as they leveraged their status as incipient Shivas. There is something here, Bagwadi-Ji said (my paraphrase), that makes people feel attracted (Hindi: akarshit) to the place. The "here" of Kedarnath pulls people. The noted Garwhali historian Shivaprasad Dabaral, citing Yashpal Jain's description of another Himalayan pilgrimage place (Amarnath), uses the same notion of attraction (Hindi: akarshan) to describe the power of the Himalaya in general. ${ }^{8}$ Unlike the pilgrimage place of Badrinath to the west, which lies on a trade route crossing into Tibet, Kedarnath is on the way to no other destination. With the exception of herders who might have brought their flocks into the end-valley to graze, there is no reason for being in Kedarnath in at least the last one thousand years that has not directly or indirectly centered on Shiva and/or the reverence accorded the source of a tributary of the Ganga (the Mandakini River). The economic benefits of being in Kedarnath are predicated on the power of the place as a magnet of persons.

Bagwadi-Ji was, I felt, speaking to me on several levels. Conscious of his local knowledge of the site, he was offering a distillation of his professional understanding of the site "on the record." But he was also deeply embedded in his own assessment. Many of the people at whom we were both looking were potential clients who might commission him to perform ritual worship (Hindi: puja) on their behalf. Part of the attraction of Kedarnath that he was describing 
is economic. He would also have surmised that those visitors who were snapping photographs of the scene were less likely to feel a strong need for his services. Like many other tirth purohits, he was aware that nature-oriented tourism is increasingly important to the growing numbers of visitors to Uttarakhand each year and knew that many people did not come to Kedarnath with the primary goal of worshipping Shiva using traditional forms of ritual practice. Thus what he was noting was that Kedarnath attracts many people each year for different reasons but that all these people inexorably find themselves in the same spot.

The magnetic power of Kedarnath creates a feeling of vulnerability, of being a small creature pulled to a place that is not primarily set up for human comfort or even survival, no matter the amount or lack of available luxury. But this sense of vulnerability can take many forms. It can mean, for those who come to Kedarnath for the purposes of livelihood, economic vulnerability-no matter how much one can earn in a single day during the high season, there is no guaranteed income. It can be medical-even hardy Garhwalis who live in Kedarnath for any length of time struggle with illness and the effects of altitude. This sense of vulnerability is, since 2013, more easily seen. But it was there before as well. There is a precariousness to being a living human and, for locals, trying to make a living at almost 3,60o meters. To stand in Kedarnath is, among other things, to feel constrained by the power of what is there, a power that is mixed up with the presence of Shiva as well as the location itself. The fragility of human presence in the mountains is a persistent fragility because mountains are always changing. The weather is always changing. The trip up the steep, narrow valley functions as a focusing mechanism for this feeling.

In thinking about the power of Kedarnath I am also reminded of a conversation about the visual experience of God's true form (Hindi: sakshat darshan) from the Kedarnath pilgrimage season of 2007 that took place during a conversation between a family of yatris from Delhi and several local men. One of the local men, whom I will call Shukla-Ji, had spent much of his adult life working in Kedarnath during the pilgrimage season. While we had been around each other many times before, it was during this conversation that Shukla-Ji decided to offer his views on Kedarnath in my presence. The following is a paraphrase of what he said. First he told the story of a man who had come to Kedarnath, entered the temple, and, upon beholding the rock linga found in the inner sanctum, experienced sakshat darshan. For him this meant that he saw an anthropomorphic, matted-hair, trident-bearing Shiva in the rock. He exited the temple and went back two more times and experienced sakshat darshan each time. However, when he went again with his family it did not happen. A woman from the yatri family offered this interpretation: "The blessing God shares with you [Hindi: prasad] is according to your faith [Hindi: shraddha]."9 I have often heard varieties of this sentiment expressed to me in Indian contexts when I am asking questions about divinity and 
experience. What a yatri brings to a place like Kedarnath determines how she or he will experience the encounter; the same could be said for a researcher. But this was not the end of the matter. As the conversation continued, the group agreed that there was something objectively distinctive about Kedarnath when compared to other famous Himalayan Hindu pilgrimage sites such as Vaishno Devi in Jammu and Kashmir. That is to say, place and divinity were not only in the eye of the beholder; the place and the deity had a say in the matter.

Shukla-Ji, normally a dignified and somewhat taciturn man, expressed this complexity with a passion indicating that this was something he had been thinking about for a long time. He said (my paraphrase) that he had been coming to Kedarnath for thirty-one years, had no reason to lie, and had never experienced sakshat darshan. On the one hand there was some power (Hindi: shakti) in the place. On the other hand, anyone could be God (Hindi: Bhagwan). I could be God. As he put it, "Heart and temple are places where people meet. People come here from all over the country and all over the world. They interact, speak with each other, and take the experience of being here [Hindi: yahan ka anubhav] with them when they leave." ${ }^{10}$ For Shukla-Ji, much of what marked Kedarnath as a special place had to do with the distinctive social interactions characteristic of a famous Hindu pilgrimage place that attracted diverse populations for diverse reasons. What exactly constituted "the experience of being here" (Hindi: yahan ka anubhav) varied, but God and shakti were both there somewhere. The experience of meeting could be internal, external, and both. Yet at the same time, hovering quietly in the conversation, was the feeling that some power (Hindi: shakti) connected to Kedarnath operated independently of what humans brought to the encounter. This is also generally felt to be the case about a Hindu tirtha or dham. Surinder Bhardwaj and James Lochtefeld $(2004,479)$ explain this understanding of tirtha as "the deeply rooted conviction that certain places are powerful in their own right."

The power that Kedarnath exercises, and that is the focus of human attention, does not consistently localize in any one spot in the end-valley where Kedarnath is located. It is found in the place as a whole-constituted through the fuzzy and dynamic interplay of person, temple, and environment. This interplay can be felt and seen as the presence of Shiva or the residue of his presence, or it can be attributed the broader power of the Himalayan environment, itself infused with the earthy and aquatic presence of the Goddess and her shakti, or both. ${ }^{11}$ It is hyperpresent but also opaque. It is attractive but cannot be grasped. It frustrates and relativizes human effort in a way that will not go away. On a good day this power is quiescent, a passive "palpable energy" (to use Lochtefeld's $[2010,201]$ term) that purifies and attracts by the mere fact of its nature rather than in a volitional, personified fashion. In May of 2007 Bhupendra was speaking with an old woman from Jaipur who had come to Kedarnath for the second time, the first being in 1992. He asked her 
about the relationship between Shiva and the earth (Hindi: bhumi) in Kedarnath. Her answer: "Lord Shiva and Kedarnath are the same thing."12

This sentiment is most easily understood visually. In trying to understand the complicated emplacedness of Shiva in Kedarnath, I found print images of Kedarnath available for purchase in the Kedarnath market to be of great use. Yatris usually purchase these images after visiting the temple and just before departure from Kedarnath. Such print images serve as souvenirs and often are ultimately installed in a home or work shrine. Some images of Kedarnath depict the linga inside the temple and show nothing else. Others simply show the temple and its panoramic Himalayan backdrop. Many images use the techniques of montage and collage to blend depictions of the inside of the temple, the external setting of the temple, and figural representations of Shiva and his partner the goddess Parvati. Looking across the available selection of print images depicting Kedarnath, one sees that Shiva is understood to be present inside the temple as the linga but also to be part of the place itself..$^{13}$

From a human standpoint, Shiva's emplaced power is not wholly compassionate. Shiva-in-Kedarnath is both hyperpresent, utterly involved in the place, and at the same time aloof and uninvolved. Kedarnath orbits this Shaiva (Shiva-oriented) paradox. I remember one day in the bazaar in 2007 when a pilgrimage priest (Hindi: tirth purohit) told me (my paraphrase) that Shiva makes a poor personal deity (Hindi: ishtadevta), that is, the form of God you choose for yourself as opposed to the form important for your family, community, or village. Bhairava or Hanuman is better, he said-they are the type of deity that gets the job done (Hindi: kam-karne-wale). Bholenath (Shiva), he said, is fickle. Who knows if he will notice you or not? And if he does, who knows if it will be beneficial. I have thought back to this comment since the floods.

\section{WORKING WITH THE IDEA OF "PLACE”}

I view experiences of Kedarnath's power as mutually constitutive encounters between person and location, and this is reflected by my use of the term place. I understand place as the overlap of culture, social location, personal history, gender, sense experience, natural environment, and economic position that emerges at a geographic location or locations over time through the interactions of the location with embodied persons. My understanding is influenced by Edward Casey's idea that "place is the most fundamental form of embodied experience" (Feld and Basso 1996, 9).14 I find particularly useful Casey's (1996, 26-27) point that places are to be understood more as events, processes, or happenings than as large, static objects. Experiences of place, like communicative acts, are continually emergent. Patterns in what continually emerges can be noted, but they are always in production and dependent on context. Casey's understanding of place is in turn predicated on an understanding of the person as an embodied subject 
who, following Merleau-Ponty, experiences herself as already embodied, already emplaced, and already connected to other embodied persons. That is to say, experiences of place are founded upon an embodiment that is inherently intersubjective. This understanding of place foregrounds an embodied, sensuous experience of being in the world. It is therefore an understanding both of place and of experience. Casey also notes, importantly, that "places gather . . . various animate and inaminate entities" (24). This sense of what Casey terms "gathering" will be important to remember.

\section{HOW EXPERIENCES OF PLACE WORK}

My understanding of experience differs somewhat from Casey's in that I think that socially, politically, and economically constituted forms of (inter)subjectivity are felt in much the same way as sense experience. This understanding builds on recent developments in phenomenological anthropology (Desjarlais and Throop 2011) or what some anthropologists term critical phenomenology (Willen 2007) or an "experience-near" analytic framework (Seeman 2009, 3-4; Wikan 1991). This approach aims to bring to articulation the experience of being in the world as it is framed by factors such as poverty, disease, illegality, trauma, and situations in which humans find themselves at the "limits of language" (Jackson 2008, xii; Seeman 2009, 3-4). A related approach is that of sensory anthropology, which has begun to think through the ways that the social is sensorially produced or understood as a kind of atmosphere (Chau 2008; Desjarlais 2003; Edensor 2007; Howes and Classen 2013).

Several related trends in geography have been pushing in a similar direction. One recent trend in critical geography, based on the work of Henri Lefebvre, looks at the ways in which the flows of money and political power through space create "spatio-temporal patterns," or rhythms (Edensor 2010) that are in important ways constitutive of human embodied experience. Others come to this way of thinking through the lens of affect. Nigel Thrift (2004, 64), for example, understands this modality of embodied geographic experience as "a sense of push in the world"-a push that "in the case of embodied knowledge . . . is provided by the expressive armoury of the human body" (see also Thien 2005). In this understanding, called by some "postphenomenological," of how places are involved with affect, landscapes are understood as the meeting point between the inner and the outer (Rose and Wylie 2006, 478; Rose 2006; Whatmore 2006). Some voices in this conversation theorize affect as something produced through processes in which humans are merely part of larger events that include a range of animate and inanimate entities (see, e.g., Lorimer 2008); this calls to mind Casey's sense of gathering. Scholars looking at place in South Asian contexts have begun to harness these theoretical tools as well (see, e.g., Sarbadhikary 2015). 
Thinking about the feel of the power of Kedarnath with reference to these ideas of experience, place, affect, and shakti allows us to see how the power of Kedarnath is produced by the concatenation of many different factors and how deeply it registers in the embodied experience of people who find themselves standing in Kedarnath. It allows us to see how the political economies of mountain pilgrimage tourism in North India and the broader regional, national, and global forces that infuse the worlds of North Indian mountain pilgrimage tourism combine and fuse in the felt experience of those standing in Kedarnath, with the sensuous experiences of high-altitude travel, Himalayan weather, and divine shakti.

\section{EXPERIENCING ECO-SOCIAL COMPLEXITY}

But how do these different experience factors, or variables, relate to one another? I think we can best understand the way that experiences of place emerge by thinking of experiences of Kedarnath as experiences of an eco-social system that demonstrates fuzzy boundaries and is characterized by complexity. ${ }^{15}$ The primary boundaries of the system are the end-valley, starting just after devdarshini and ending with the snout of the Chorabari glacier behind the village. The fuzziness of these boundaries can be illustrated linguistically. The term Kedarnath usually means only the village, or the temple. In the worlds of Puranic and Upapuranic Sanskrit texts, however, the words kedara and kedaramandala sometimes refer to the entire area of Garhwal and sometimes more specifically to the Kedarnath locale. There were temples to Shiva in his Kedareshvara form throughout the Indian subcontinent and even in Southeast Asia by the end of the first millennium CE. Heuristically limiting the primary field of analysis to the Kedarnath end-valley makes it possible to see patterns in the power of the place that would be lost at larger or smaller scales. ${ }^{16}$

The idea of eco-social complexity can be understood as the idea that humans and other elements of the world-organism each function as multiscale systems that exist in dynamic and nonlinear relation to one another (for an overview of this set of ideas, see Haila and Dyke 2006, 279-301). Embodied persons, water, rock, weather, ice, mud, horses, helicopters, buildings, money, social authority, political power, cement, stories, rituals, emotions, affects, Shiva, and shakti are all elements in the system and, if we refocused the unit of analysis differently, could be themselves understood as systems. Kedarnath is a complex system because there is no single predictable shape to how these different elements relate to and combine with one another. Rather, their relationship to one another is nonlinear. Environmental philosophers, environmental scientists, environmental historians, and environmental anthropologists use the idea of eco-social complexity to think about the patterns that connect the "sociocultural dynamics" found 
in human social systems with the complex systems of weather and climate (Haila and Dyke 2006, 17). Thinking about Kedarnath as a complex system also further underscores the necessity for broad sociohistorical contextualization. Complex systems are often characterized by their "extreme sensitivity to initial conditions," which means that the earlier history of how Shiva's presence in Kedarnath (and in the Himalaya more broadly) has been understood is in my view critical for understanding the shape of things closer to the present (Damon and Mosko 2005, 10). The idea of eco-social complexity also aids in conceptualizing Kedarnath-place-deity as agentive. Complex agency may be understood as the application of the idea of complexity to the notion of agency. It is the demonstration of coherent, dynamic, and "persistent patterns" of agency or action by a system of smaller elements or systems that appear to act in concert as part of a dynamic network (such as an economic system), a number of smaller entities or systems of different scales that overlap in a connected way (F. Cho and Squier 2013, 367-68). ${ }^{17}$

The complex system of Kedarnath is a system that can be characterized as an eco-social system. The idea of eco-sociality is an important tool for those who aim to think about the world in a way that does not place the human individual and human society at the center and regard the rest of the world as somehow set apart or separate from the human world. For example, Eduardo Kohn (2013) understands the relationship between humans and forests as relations between self-organizing and emergent systems that overlap and take account of each other. Tim Ingold (2000, 189-218) thinks of landscape as an ongoing, embodied, material dialogue between human and environmental organisms. Viewed in this way, disasters remind humans that their relationship to the natural world is an ongoing part-whole relationship. The routine occurrence of earthquakes, landslides, and floods that frame life in the Himalaya is a forceful reminder that eco-sociality is a basic feature of human existence. This understanding of eco-sociality also adds to the phenomenological idea of intersubjectivity mentioned earlier by noting that the intersubjectivity that is at the root of being in the world includes many different kinds of subjects, of which humans are but one subset.

My overall approach, the idea that we should think about experiences of the power of Kedarnath as experiences of a place that functions as a complex eco-social system, should be understood as a holistic, ecological approach. This way of thinking about Kedarnath is meant to showcase the potential offered by the discipline of religious studies for approaching global questions of critical importance to human life in the twenty-first century. Religious studies (ironically, given the European and more broadly Western history of the discipline) is useful not because I claim that it is itself a holistic discipline but because much of the data that it considers contains models of embodied personhood that connect to holistic worldviews, worldviews that frame human life as one part of a larger system that 
inflects across "differing scales" (Handelman and Lindquist 2011, 21). I rely upon the understanding of ecology fashioned by John Grim and Mary Evelyn Tucker $(2014,62)$ as part of their decades-long project to create a theoretical space for the study of ecology and religion: that which "locates humans within the horizon of emergent, interdependent life and does not view humanity as the vanguard of evolution, nor as the exclusive fabricator of technology, nor as a species apart from nature." For Grim and Tucker this commitment entails attending to how cosmological understandings embed in daily life. This kind of holistic treatment avoids offering further support to the deeply problematic and globally influential modern Western nature-culture binary, a binary that scholars such as Mabel Gergan, Ritodhi Chakraborti, Mona Bhan, and Andrew M. Bauer have argued continues to persist in ways of thinking about "the Anthropocene. ${ }^{18}$ In thinking in these holistic ways I am also following the direction suggested by Manuel Vásquez (2011, 204-5), who has argued that a particular kind of holistic approach, what he terms (following Evan Thompson and Francisco Varela) "relational holism," might serve as a theoretical charter for religious studies.

The idea that the religious dimensions of the situation are somehow separable from the situation of the place as a whole is another intellectual predisposition this book seeks to undo. In one sense it could be said that in this book I use the analytic category of place to examine the overlap of political, economic, cultural, social, religious, and environmental factors in the lived experience of Kedarnath. Ultimately, however, the goal of doing things in this way is to provoke the realization that this idea of "overlap" is based on a false premise-that there are separate categories that overlap. Conversations about sustainable development, colonialisms and postcolonialities, climate change, political economy, religion, spirituality, nationalism, and modernity still appear to many to be putatively separate yet interconnected phenomena. We are moving past this assumption of categorical, a priori difference, with those who study geography and "environment" across the humanities, social sciences, and sciences leading the way. But there are still taxonomies to unthink, and ironically, given the Western origins of the concept of religion, the doing of ecology and religion can help in this regard. It is rare that scholars of tourism or Himalayan development seriously engage, for example, with the technical details of Shaiva (Shiva-oriented) philosophy. David Haberman (2013) laments an analogous kind of taxonomical myopia when he discusses how Western scholars, for the most part, were unable to comprehend the centrality of tree worship to South Asian religious worldviews because they were unable to see trees as potentially living beings in a way close to how humans are living beings. Should this blindness be cured, Haberman argues, Western ways of thinking might eventually take a more inclusive path. In the case of phenomena such as pilgrimage tourism, Himalayan development, and climate change in the twenty-first century, a commitment to start at the overlap might ultimately create the conditions for better long-term planning and a greater willingness to act 
with foresight in ways that keep religion, ecology, and development in the same conversation.

\section{SACRED PLACES}

Recent work in the study of religion on pilgrimage, space, and place has concerned itself with testing and critiquing the utility of two famous theoretical approaches that shaped a great deal of scholarly work in the late twentieth century. The first is the contention of Mircea Eliade that sacred power can be generated directly by or is intrinsically present in a physical location. The second is the contention of Victor and Edith Turner that journeys to places of religious significance (and by extension the places themselves) occasion a collective feeling of communitas, a powerful and transformative temporary erasure and inversion of normal social relations.

Several different strategies for engaging these approaches in some way or other acknowledge that certain physical locations in the world demonstrate a distinctive power of some sort, a power characterized by the often-ritualized journey of people to that location. The first is to preserve the use of the term sacred and to return to the Durkheimian roots of the idea of the sacred, regarding it as a form of power primarily constituted by social forces. As Jacob Kinnard $(2014,2)$ puts it: "It seems almost self-evident to say that religiously charged places and spaces, as well as the images associated with them, become powerful because they are made powerful. That is to say there is nothing inherently sacred about any place or space or physical object; human agents give them power and maintain that power." In the Durkheimian sense, "things sacred" are collectively designated-they are set aside from profane things through mechanisms of community and society. The Turnerian idea of communitas similarly posits a certain kind of social unity, albeit a temporary one. In recent decades this presumption of social unity has been challenged and to some degree replaced by a model that regards social contestation and conflict as the most salient social factors (Coleman 2002; Coleman and Eade 2004; Chidester and Linenthal 1995).

Another approach is to reject the utility of the term sacred. There are several linked reasons for this rejection. One is that the Eliadean echoes of the term imply the independent existence of "the sacred" as a transcendent entity, something that some recent conversations in the study of religion now question. Another reason is that it is not a term of any heuristic utility because, as a function of its post-Enlightenment Western origin, it presumes a strict separation of sacred/ profane or sacred/secular that either is not present in the example under consideration or is produced in ways that are so robustly contingent and fluid that it does not make sense, even heuristically, to posit the binary. For example, Kama Maclean $(2008,9)$, in her work on the recent origins of the Kumbha Mela, asserts that "the assumption of distinct spheres of secular and sacred activity has 
obfuscated a clear understanding of pilgrimages as powerful material forces." In the case of pilgrimage in Japan, Ian Reader $(2014,15)$ has argued that that the "dynamics of the marketplace ... are not antithetical to pilgrimage (or to 'religion'), but crucial to its successful functioning, development, appeal, and nature." Sarah Thal (2005), using examples drawn from Japanese contexts, has demonstrated that particular constellations of social, political, and economic forces can over centuries transform the character of a particular pilgrimage place almost beyond recognition.

Thus of paramount importance today in the study of religion is the recognition that places and spaces of religious significance are mutable, human products that wear diverse and historically contingent faces. Today many studies of locations possessing sociocultural, "religious" significance emphasize the diversity and multiplicity of how people experience such places. In his recent and definitive study of the Hindu pilgrimage place of Haridwar, just several hundred kilometers to the south of Kedarnath, James Lochtefeld $(2010,5)$ argues strongly for the idea that the city can be understood only through "multiple narratives." In their recent edited volume on Varanasi, Martin Gaenszle and Jorg Gengnagel $(2006,8)$ succinctly summarize a welter of anthropological literature on this point: "The rich literature of an anthropology of space and place has shown that there is great variety in the ways 'sites' are culturally constructed, and that one and the same place may be seen rather differently by different actors."

However, the emphasis on the constructed, multiple, and changeable character of place and pilgrimage, by design, does not aim to fully register the depth and material, experiential weight of what some people find some of the time when they travel to or reside in such places. Jacob Kinnard (2014, $\mathrm{xv}-\mathrm{xvi}$ ) is, I think, attentive to this issue. He bases his exploration of the religiosity of places in the modern world in the models of Henri Lefebvre and Edward Soja that posit three interwoven levels of spatial experience: the materiality of location (Firstspace), "imagined space" (Secondspace), and lived realities of the everyday where these two "intertwine" (Thirdspace). This model is a usefully flexible way of approaching many places of religious significance, particularly if, like Kinnard, one is trying to look across a number of examples that are very different from one another (in Kinnard's case Tarapith, Ground Zero, Bodh Gaya, Karbala, and Devils Tower National Monument). My approach follows Kinnard but places, relatively speaking, greater weight on the felt experience of place.

\section{THE ECO-SOCIALITY OF SACRED PLACES}

Recent decades have seen scholars across the humanities and social sciences using the ideas of flow, system, and network to theorize, in many different ways, the nuances of how embodied persons experience being in a world constituted by 
the material weave of other persons; objects; biological, social, political, and economic processes; relations of power; symbols; ideas; life forms; and environments. These ideas are now part of the always-changing toolbox of religious studies. ${ }^{19}$ One prominent voice in these conversations, Manuel Vásquez (2011, 319), has specifically urged scholars in the study of religion to draw on the study of ecology in order to better grasp the nuances and textures of these complex systems of material, embodied experience. This way of thinking about religious experience functionally rejects the idea of the sacred as a separate and immutable feature of the world and instead shows how the materiality of the world assembles in concert with the cultural and the biological in ways that become religiously powerful. I understand these approaches as attempts to account for religious power and experience that are simultaneously nonreductive and nonessentialist. Approaching Kedarnath as a complex eco-social system whose complex, eco-social character emerges in conversation with embodied persons thinks in concord with these trajectories but in a way that focuses with urgency on a particular place and emphasizes the part-whole relationship of humans to the world in which we are resident. The protean power of Kedarnath arises out of the conversation of environment, society, culture, deity, and person and does not reduce to any single feature of the place. My theoretical synthesis also attempts to bridge some of the analytic distance between these approaches and the cosmology-based framework of Grim and Tucker by attending closely to the material, political, economiccontingent-aspects of exactly how cosmologies are embedded in the everyday. In this regard I follow the direction mapped in in the recent edited volume Nature, Science, and Religion: Intersections Shaping Society and the Environment (Tucker 2012). Politics, money, weather, environmental history, theories of sustainable development, the dynamic interplay of Shiva and shakti-all come together, in highly contingent ways, in the experience of people who find themselves standing in the marshy ground of Kedar.

\section{THE STRUCTURE OF THIS BOOK}

The persistent pattern of Kedarnath-as-place is the primary character in the plot of this book. After 2013, the life story of this persistent pattern of place now divides into a "before" and "after." I want to both honor and resist this division. I follow the "persistent pattern" from its historical beginnings in the second part of the first millennium CE into the apda (disaster) and through the beginnings of the post2013 tale of the place in a way that serves as an act of testimony about what was lost, interrogates the preconditions of the disaster, and interprets the beginning post-2013 stages of the continuing complex processes of this place. That is the story of this book-how increased pilgrimage tourism, unsustainable development, and a twenty-first-century monsoon collided with a famous dham (Hindi: abode) of 
Shiva in the Himalaya, why the collision had the force that it did, and what can be learned from the collision.

Chapter 1, "In Pursuit of Shiva," uses the story of the pursuit of Shiva by the Pandavas to introduce the Kedarnath of recent times. I introduce the social worlds of Kedarnath and discuss how I fit in to those worlds. I argue that the purificatory power of the place and the character of the god resident in the place call into question the necessity of approaching the place with virtuous conduct and purity of intention, a narrative framing that surrounds the present. Chapter 2, "Lord of Kedar," examines the history of Shaivism in Uttarakhand and treatments of Kedarnath in Puranic and tantric texts. Here I argue that the shape of the Kedarnath linga indexes an archaic and specifically Himalayan understanding of Shiva's enmeshing with the world that has been formative in creating the "persistent pattern" of the place as a whole. Chapter 3, "Earlier Times," examines how Kedarnath transformed from a remote destination for renouncers and kings into a popular destination for pilgrimage tourism located in a state famous for its environmental activism. The geographic remoteness of the dham intensified the impact of the changes brought on by new statehood and a massive rise in the number of yatris coming to Kedarnath in ways that reflect the turbulent environmental history of the region.

Chapter 4, "The Season," describes what Kedarnath looked like during my fieldwork in 2007 and 2008. I show how the place was bursting at the seams and note that many of the traditional modalities for visiting and living in the tirtha had begun to drop away. In 2013 the waters descended, and chapter 5, "When the Floods Came," tries to tell the story of those early days and weeks surrounding the floods in June 2013. Then, in chapter 6, "Nature's Tandava Dance," I unpack early reactions to the disaster to demonstrate how new factors (development and tourism) joined and changed the connotative and experiential web connecting Shiva and prakriti (Hindi: nature, also a form of the Goddess in some contexts) in Kedarnath. Chapter 7, "Topographies of Reinvention," concludes by reviewing the present situation and reflecting on the broader lessons that can be learned from a close examination of Kedarnath. 